\title{
Consultas populares y referendos constitucionales sobre la protección a la naturaleza: la eficacia de la democracia directa en Ecuador
}

\section{Popular consultations and constitutional referendums on protection of nature: the effectiveness of direct democracy in Ecuador}

\author{
Viviana Morales Naranjo
}

Recepción: 31-05-2020

Aceptación: 13-07-2020

\section{Resumen}

La Constitución ecuatoriana garantiza el derecho a la participación ciudadana a través de la democracia directa, la misma que prevé varios mecanismos que permiten que el pueblo pueda intervenir en la administración del Estado. En ejercicio de la democracia directa, Ecuador ha celebrado dos consultas populares y un referendo sobre tres temas, que como veremos más adelante, están encaminados a efectivizar la protección de la naturaleza: 1) prohibición de espectáculos que tengan por finalidad dar muerte a un animal; 2) prohibición de explotación minera bajo ciertas circunstancias; y, 3) limitación a la explotación petrolera en el Parque Nacional Yasuní. Esta investigación pretende analizar la eficacia y la efectividad que ha tenido el pronunciamiento popular reflejado en las urnas, todo esto a la luz del artículo 71 de la Carta Magna que reconoce a la naturaleza como sujeto de derechos.

Palabras Clave: referendo; consulta popular, derechos; naturaleza

\section{Abstract \\ The Ecuadorian Constitution guarantees the right to citizen participation through direct democracy, which provides for several mechanisms through which the people can intervene in the administration of the State. In the exercise of direct democracy, Ecuador has held two popular consultations and a referendum on three topics of protection of nature: (1) prohibition of shows aimed at killing an animal; (2) prohibition of mining under certain circumstances; and, 3) limitation on oil exploitation in Yasuní National Park. This research seeks to analyze the effectiveness of the popular pronouncement reflected in the ballot box, all in light of Article 71 of the Constitution which recognizes that nature is subject to rights.}

Keywords: referendum; popular consultation, rights; nature 


\section{Introducción}

Squealer, anunció que por un decreto especial del camarada Napoleón se había abolido Bestias de Inglaterra. (...) Bestias de Inglaterra fue el canto de la Rebelión. Pero la Rebelión ya ha terminado. (...) En Bestias de Inglaterra nosotros expresamos nuestras ansias por una sociedad mejor en lo futuro. Pero esa sociedad ya ha sido establecida. (...) En su lugar Mínimus, el poeta, habia compuesto otra canción que (..) se cantó todos los domingos por la mañana después de izarse la bandera. Pero, por algún motivo, a los animales les pareció que ni la letra ni la música estaban a la altura de Bestias de Inglaterra.

George Orwell (1945)

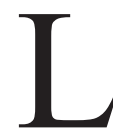

os Estados, a más de incorporar un derecho reclamado por la sociedad civil en el ordenamiento jurídico, tienen la obligación de crear los mecanismos idóneos para dotarlo de efectividad y eficacia. Por un lado, la efectividad de la norma, de acuerdo a Díez-Picazo, depende de dos tipos de factores: que los destinatarios adopten las conductas que la norma dispone (la espontánea absorción de la norma por la vida social) y que la norma sea aplicada por los jueces y órganos de aplicación en general (DíezPicazo, 1999, p. 206). Por otro lado, la eficacia de una norma, analizada no desde un punto de vista jurídico clásico ${ }^{1}$ sino desde un enfoque sociológico jurídico, está encaminada a analizar los efectos reales que consigue una norma en correspondencia con los fines de quien la ha producido (Ferrari, 2015, p. 84). De ahí que Rolando Pavó defina a la eficacia social de una norma como "el cumplimiento de los objetivos volitivos propuestos con su creación, es decir, cuando se logran los propósitos económicos, sociales y políticos como derivado del hecho de que la norma se cumpla, obteniéndose los fines sociales previstos" (2016, p. 1).

Tomando en cuenta que la eficacia jurídica está encaminada a evidenciar si los propósitos económicos, sociales y políticos de una norma se cumplieron o no, cabe previamente tener claridad respecto al fin que persigue una norma. Rubén Héctor Donzis parte de la sociología jurídica para

1 Para Kelsen la eficacia de una norma es el cumplimiento de las misma o, en caso de incumplimiento, su aplicación por el juez (Kelsen, 1979, 24) 
afirmar que una norma puede perseguir: 1) una distribución de valores en la sociedad (económicos, culturales o espirituales), 2) una función represiva de conductas negativas, 3) una función promocional de conductas que se consideran positivas (2006, p. 12).

Por lo expuesto, esta investigación, con enfoque cualitativo, se centra en el análisis político-jurídico de la eficacia que tuvieron los resultados de las dos consultas populares y el referendo sobre la protección de la naturaleza, en los 3 casos en concreto que se revisarán. Para ello, en una primera parte se explicarán los mecanismos a través de los cuales se ejerce la democracia directa en Ecuador. En una segunda parte, se revisará el grado de eficacia de la consulta popular sobre la protección animal de 7 de mayo de 2011. En una tercera parte, se abordará el grado de eficacia del referendo y de la consulta popular de 4 de febrero de 2018 que limita la actividad minera y otorga protección al Yasuní, respectivamente.

\section{Mecanismos para la democracia directa en Ecuador}

La participación es fundamental en un Estado democrático porque constituye "el proceso a través del cual distintos sujetos sociales y colectivos, en función de sus respectivos intereses y de la lectura que hacen de su entorno, intervienen en la marcha de los asuntos colectivos con el fin de mantener, reformar o transformar el orden social y político" (Velásquez, González, 2004, p. 2). El art. 95 de la Carta Magna reconoce el derecho de participación a través de la democracia representativa, directa y comunitaria. Las siguientes líneas se centran en el estudio de la democracia directa como mecanismo de participación.

La democracia directa es definida por Lincoln (1863) como un régimen político en el que el pueblo ejerce directamente el poder; es decir, "un gobierno de la gente, por la gente, para la gente". De acuerdo a la sección cuarta de la norma suprema ecuatoriana denominada "Democracia directa" existen varias formas a través de las cuales el pueblo puede involucrarse en la administración del Estado: la iniciativa popular normativa (art. 103), la consulta popular sobre temas de interés general (art. 104), la revocatoria de mandato de autoridades de elección popular (art. 105); y, el referéndum 
(art. 106). Esta investigación se limita al análisis de las consultas populares y referendos que se han realizado en Ecuador en temas de protección a la naturaleza, específicamente en lo que se refiere al art. 71 de la Carta Magna que señala:

La naturaleza o Pacha Mama, donde se reproduce y realiza la vida, tiene derecho a que se respete integralmente su existencia y el mantenimiento y regeneración de sus ciclos vitales, estructura, funciones y procesos evolutivos.

Toda persona, comunidad, pueblo o nacionalidad podrá exigir a la autoridad pública el cumplimiento de los derechos de la naturaleza. Para aplicar e interpretar estos derechos se observarán los principios establecidos en la Constitución, en lo que proceda.

El Estado incentivará a las personas naturales y jurídicas, y a los colectivos, para que protejan la naturaleza, y promoverá el respeto a todos los elementos que forman un ecosistema.

El voto directo de la población permite que ésta exprese su opinión a través del pronunciamiento popular respecto a una pregunta que puede ser de dos tipos: consulta popular o referéndum. La jurisprudencia constitucional ha señalado la diferencia entre ambos términos. Por un lado, el referéndum implica someter a consulta popular la aprobación de un texto normativo -o propuesta normativa- concreto (Dictamen No. 2-19-CP/19, 20 de junio de 2019). Un referendo cabe tanto para enmiendas como para reformas constitucionales. La iniciativa para enmendar o reformar la Constitución puede provenir del presidente, del apoyo mayoritario de la Asamblea Nacional o de la iniciativa ciudadana, siempre que esta última cuente con el respaldo de al menos el $8 \%$ de apoyo del padrón electoral -en caso de la enmienda- y con el 1\% de apoyo en caso de reforma constitucional (CRE, art. 441, 442).

Por otro lado, la consulta popular -a la que la Corte Constitucional denomina plebiscito- consulta una decisión sobre un tema de relevancia pública, sin someter a aprobación un texto normativo definido. (Dictamen No. 2-19-CP/19, 20 de junio de 2019). El art. 444 de la Carta Magna establece la potestad que tiene el presidente, las 2/3 parte de la Asamblea Nacional o 
el $12 \%$ de la población para promover una consulta popular a fin de conocer la voluntad popular respecto a la creación de una nueva Constitución a través de la Asamblea Constituyente. Adicionalmente, el art. 104 de la norma suprema prevé la posibilidad de convocar a una consulta popular a iniciativa del presidente, de un gobierno autónomo descentralizado-GADy de la ciudadanía sobre cualquier asunto. Las iniciativas populares son el mecanismo de democracia directa por excelencia ya que permiten que los electores se pronuncien sobre una medida política, constitucional o legislativa propuesta por un cierto número de ciudadanos (International Institute for Democracy and Electoral Assistance, 2009, p. 4). Por lo tanto, la iniciativa popular representa el involucramiento del pueblo en la toma de decisiones públicas a través de una propuesta que emana del deseo popular de conocer lo que la ciudadanía opina respecto a un asunto que es de considerado de interés general.

Las consultas populares y los referendos son sumamente beneficiosos para el pleno ejercicio de la participación ciudadana y de manera general para la democracia, puesto que el art. 106 de la Carta Magna establece que el pronunciamiento popular será de obligatorio e inmediato cumplimiento. Por lo tanto, estamos frente a dos mecanismos jurídicos que permiten que las decisiones trascendentales del Estado sean tomadas a través del consenso mayoritario e impiden la vigencia de normas que beneficien únicamente a los grupos hegemónicos que detentan el poder o que tienen estrechos vínculos con este. Partiendo de la frase platónica que afirma que "El precio de desentenderse de la política, es el ser gobernado por los peores hombres", la participación ciudadana se convierte en un presupuesto indispensable para alcanzar la eficacia de los derechos reconocidos constitucionalmente y evitar actuaciones abusivas por parte del poder público.

El ejercicio de la democracia directa en Ecuador se ha dado respecto a temas de diversa índole: enriquecimiento ilícito, seguridad social, funcionamiento y competencia de instituciones, entre otros. La protección de la naturaleza tampoco ha escapado al pronunciamiento ciudadano. Efectivamente, el ejecutivo, haciendo uso de su potestad constitucional para convocar a referendos y consultas populares, ha recurrido a la democracia directa en dos ocasiones-7 de mayo de 2011 y 4 de febrero de 2018-, a fin 
de conocer la opinión ciudadana respecto a la forma en que deben tutelarse tres elementos de la naturaleza: 1) los animales destinados al entretenimiento humano, 2) los territorios urbanos en los que se pretendió limitar la minería; y, 3) el Parque Nacional Yasuní en donde se persiguió la limitación de la extracción petrolera. Como veremos más adelante, dichas iniciativas presidenciales se llevaron a fin de dar cumplimiento a lo establecido en el art. 71 de la Constitución que reconoce el derecho a la protección y a la reparación que tiene cada uno de los elementos de la naturaleza, a fin de garantizar el mantenimiento y regeneración de sus ciclos vitales, estructura, funciones y procesos evolutivos. Consecuentemente, estamos frente a un cambio de paradigma respecto a la forma en que debe relacionarse el ser humano con la naturaleza en los casos específicos sometidos a votación popular. Dicha transición ética recogida por la norma suprema no puede ser desconocida por el aparataje estatal; de ahí que, en los siguientes apartados, se analice la eficacia de cada una de las preguntas planteadas por el presidente de la república en su rol de garante de los derechos constitucionales.

\section{La eficacia de la Consulta Popular sobre la protección animal: las implicaciones de los espectáculos cuyo fin es dar muerte a un animal}

Son varias las actividades económicas que tienen por fin entretener a los seres humanos a costa del maltrato animal: peleas de perros, toros de pueblo, peleas de gallos, corridas de toros, etc. En las siguientes líneas nos centraremos en el análisis de dos espectáculos que conllevan al maltrato y muerte de los animales: corridas de toros y peleas de gallos. Cabe señalar que como producto de la colonización española se consolidaron prácticas culturales que reflejan el sincretismo y la consecuente aceptación de ciertos espectáculos de entretenimiento, por una parte de la población ecuatoriana. Dichos eventos culturales están caracterizados por infringir dolor a los animales en su calidad de seres sintientes. Al respecto Monterín señala:

Cultura es toda información transmitida por aprendizaje social, y eso incluye ideas y costumbres de todo tipo. (...) Lo cultural no tiene por qué ser bueno o deseable en sentido alguno. Todo lo que se transmite por medios no genéticos es cultura, por malo o indeseable que nos pueda parecer. Tanto la ciencia como la superstición son cultura, y 
también lo son la democracia y la dictadura, el cosmopolitismo y el nacionalismo, la delicadeza del ballet clásico y el cutrerío de las corridas de toros. El adjetivo "cultural" no es laudatorio, sino meramente descriptivo, y no implica juicio de valor alguno (Monterín, 2014, p. 97).

Con base en lo expuesto, se procede a explicar brevemente la forma en que se usó la consulta popular como medio para dirimir la controversia ética y política que rodea a los espectáculos taurinos y las peleas de gallos.

A) Las corridas de toros

Desde la introducción de la tauromaquia en Quito en 1770 (Guevara, 2013 , p. 1) se ha mantenido una eterna disputa entre taurinos ${ }^{2}$ y animalistas ${ }^{3}$ respecto a las violaciones constitucionales que acarrean las corridas de toros. Por un lado, los taurinos sostienen la validez de las corridas con base en cuatro derechos: derechos de libertad, derecho a la cultura, derecho al trabajo y derechos de las minorías. Por otro lado, los animalistas se oponen a este espectáculo fundándose en la necesidad de proteger al toro de lidia, en tanto que elemento de la naturaleza y ser sintiente. A fin de dar solución a esta disputa ético-jurídica, el 7 de mayo de 2011, el ex presidente de la RepúblicaRafael Correa-, mediante plebiscito presentó un proyecto de consulta popular que contenía diez preguntas de diversa índole. La pregunta que nos atañe, puso a consideración de la ciudadanía lo siguiente: ¿Está usted de acuerdo que en el cantón de su domicilio se prohíban los espectáculos que tengan como finalidad dar muerte al animal? Cabe señalar que, a pesar de ser una pregunta que tiene como finalidad proteger a los animales, esta no incluyó en su contenido la afirmación de que los animales son sujetos de derechos.

La Corte Constitucional del Ecuador, órgano competente para emitir un dictamen previo sobre la constitucionalidad de cada pregunta, determinó la viabilidad de la propuesta haciendo dos aclaraciones: 1) La abolición de este tipo de espectáculos debía darse a nivel cantonal y no nacional, por

2 De acuerdo a la Real Academia de la lengua Española (RAE), taurino es el aficionado a los toros.

3 De acuerdo a Nathalia Castañeda, animalistas son quienes consideran que la sostenibilidad no está en el aspecto económico sino en el bioético y medioambiental. 
cuanto se debía preservar la capacidad normativa de los gobiernos locales en el ámbito de sus competencias. 2) Los Consejos Municipales de los cantones en que hubiese ganado el SI, debían desarrollar una ordenanza que regle las limitaciones a las corridas de toros (Corte Constitucional del Ecuador-CC-, Dictamen No. 001-DCP-CC-201, 15 de febrero de 2011). Los resultados de la consulta arrojaron que, 125 de 221 cantones estaban de acuerdo con la prohibición de este tipo de espectáculos (R.O. supl. $\mathrm{N}^{\circ} 490,13$ julio del 2011). Sin embargo, esta pregunta no tuvo la eficacia deseada por su promotor. Efectivamente, en el proyecto de consulta popular, el presidente de la República afirmó la importancia de detener los actos de crueldad animal al amparo de lo que establece el artículo 71 de la Carta Magna:

El artículo 71 y siguientes CRE, reconoce y eleva a la categoría de derechos constitucionales, los derechos de la naturaleza, en contra de los cuales están todas las acciones que impliquen por espectáculo, diversión o sadismo, algún tipo de tortura o destrucción de los seres que forman parte de la pachamama, por lo cual es hora de debatir si se debe declarar al Ecuador libre de espectáculos públicos en los que se mate a los animales por simple diversión ( Oficio N. ${ }^{\circ}$ T. 5715SNJ-11-55, 17 de enero del 2011).

A pesar que en Quito, el 54,43\% se pronunciaron en contra de los espectáculos que tengan por fin dar muerte a un animal (R.O. supl. $\mathrm{N}^{\circ} 490,13$ julio del 2011), el 3 de octubre de 2011, el ex alcalde de Quito-Augusto Barrera-, aprobó la Ordenanza Metropolitana de espectáculos taurinos N. 127, en la que se mantiene la autorización para celebrar corridas de toros, espectáculo que estaba autorizado jurídicamente desde el año 2003. Así, contrariando la voluntad de los quiteños expresada en las urnas, esta disposición reconoce a los espectáculos taurinos como tradición ancestral de los quiteños, haciendo recaer sobre los hombros del Municipio el deber de fomentarlos y difundirlos como acervo cultural y elementos irrenunciables de la identidad histórica de Quito. Cabe señalar que la permisión que se mantiene respecto a estos espectáculos radica en las varias interpretaciones que se han dado respecto a esta pregunta, tanto por parte de los taurinos como parte de los animalistas; todo esto, en razón de la ambigüedad respecto a si las corridas de toros tienen por finalidad dar muerte al animal o entretener a 
los espectadores con base en el sufrimiento animal. ${ }^{4}$

Como respuesta a la emisión de la norma citada, el colectivo animalista Diabluma, invocando el art. 106 de la CRE que señala que los resultados de la consulta popular son de cumplimiento obligatorio para las autoridades públicas, presentó una Acción pública de inconstitucionalidad en contra de la Ordenanza No. 127, con la finalidad de que se deroguen ciertos artículos calificados como contrarios a la voluntad popular expresada en las urnas el 7 de mayo de 2011. A pesar de que han transcurrido nueve años desde la presentación de la demanda, el colectivo Diabluma todavía se encuentra a la espera de pronunciamiento por parte de la Corte Constitucional (Acción de inconstitucionalidad No. 0056-11-IN, 18 de noviembre de 2011).

No obstante, cabe resaltar que el 9 de junio de 2020, el Concejo Municipal en Sesión No. 071, aprobó el proyecto de Ordenanza que elimina el Capítulo III de los espectáculos Taurinos del Código Municipal argumentando la necesidad de dar cumplimiento a los resultados de la consulta popular de 2011. Este viraje normativo evidencia que no bastó con que el pueblo se pronuncie en 2011 para que se prohíban las corridas de toros, sino que fue necesario que llegue un gobierno municipal favorable a la protección a los animales para que se dé eficacia y efectividad al art. 106 de la CRE que establece que los resultados de las consultas populares son de cumplimiento obligatorio.

B) El incumplimiento de la voluntad ciudadana a causa de las peleas de gallos

Las peleas de gallos se popularizaron en Sudamérica en el siglo XVI, con la llegada de los españoles a América, quienes realizaban estos espectáculos en las cubiertas de los barcos que partieron a las Indias y representaban una actividad que permitía a los navegantes romper con la monotonía (Bethencourt, 1982, p. 482). Como consecuencia de la consulta popular de 7 de mayo de 2011, varios cantones como Mira, Catamayo, Guayaquil, Manta, Rocafuerte, Otavalo y Cayambe se pronunciaron

4 Para ahondar este tema leer: Viviana Morales Naranjo, Las corridas de toros en Ecuador. Deconstruir la cultura taurina para construir los derechos de los animales", FORO Revista de Derecho, UASB, N. 34 (julio-diciembre 2020 
favorablemente por la abolición de estos espectáculos. No obstante, en dichos cantones se continúan celebrando ferias de peleas de gallos y hasta el momento no existe ninguna ordenanza municipal que prohíba este tipo de prácticas (La Hora, 29 de agosto de 2018).

Por otro lado, en cantones conocidos por sus peleas de gallos, como Gonzanamá y Loja, en los que la mayoría de votantes se pronunciaron por el $\mathrm{NO}$, tampoco existe ordenanza alguna que regle las condiciones bajo las cuales se deben desarrollar las actividades galleras, a pesar de que la Defensoría del pueblo ha exhortado a los Gobiernos Autónomos Descentralizados a que establezcan diálogos con quienes practican este tipo de espectáculos y con quienes acuden a estos recintos a fin de que se incentive su erradicación paulatina puesto que estos contribuyen a una cultura violenta (Resolución No. 014-DPE-DINAPROT-56656-2013, 12 de junio de 2013). Adicionalmente, los grupos de cabildeo encabezados por comerciantes y criadores de gallos recurren constantemente a los municipios para que se deje sin efecto cualquier intento de ordenanza que prohíba las peleas de gallos. A modo de ejemplo, en el cantón Antonio Ante donde ganó el SI con un 56.75\%, en 2014 se aprobó una ordenanza municipal que prohibía las peleas de gallos donde se dé muerte al animal. Sin embargo, a fin de dejar sin efecto esta norma, los propietarios de gallos acudieron a sesiones del Consejo Municipal alegando que las contiendas de gallos constituyen una actividad de tradición ancestral y entretenimiento, en la que no se provoca la muerte del animal por mano humana (La Hora, 4 de noviembre de 2015). La autoridad municipal optó por dejar sin efecto la prohibición y actualmente se siguen celebrando peleas de gallos, al igual que, en cantones como Guayaquil y Quito donde también prevaleció el apoyo a la abolición de este tipo de espectáculos (Código municipal del DM de Quito, Capitulo II).

C) Efectos jurídicos de la consulta popular sobre los animales

La consulta popular de 7 de mayo de 2011 permitió que, por primera vez, se cuente con la opinión ciudadana respecto al grado de protección que ameritan tener los animales como elementos de la naturaleza. No obstante, esta consulta estuvo precedida de un grave defecto al momento de efectuar el control material realizado por la Corte Constitucional. Este órgano judicial, 
por un lado, seccionó bajo la voluntad de cada cantón el ejercicio de ciertos derechos reconocidos por la Constitución a favor de la naturaleza, cuando en realidad la consulta debió tener resultados a nivel nacional, puesto que los derechos de la naturaleza se reconocieron a favor de toda la biodiversidad que se encuentra en Ecuador. Por otro lado, la alta corte, al exigir que se modifique la pregunta bajo los lineamientos señalados por dicho órgano de control, generó una absoluta ambigüedad sobre los fines que perseguía la pregunta sometida a consulta popular.

Cabe señalar que el pronunciamiento de la ciudadanía no tuvo la efectividad y la eficacia esperada. La falta de efectividad se evidencia, por un lado, en la desobediencia por parte de los taurinos y galleros quiteños que continuaron organizando y asistiendo a este tipo de espectáculos a pesar de los resultados reflejados en las urnas; todo esto, en razón de la mencionada ambigüedad de la pregunta sometida a consulta popular. Por otro lado, los funcionarios públicos de ciertos cantones en los que ganó el SI continuaron emitiendo disposiciones contrarias a la voluntad popular para permitir la celebración de estos espectáculos. De igual modo, el legislador, al momento de aprobar el Código Orgánico del Ambiente-CODA-, en vigor desde el 12 de abril de 2018, se limitó a prohibir las corridas de toros en los cantones en los que ganó el SI en la consulta popular del 7 de mayo de 2011; sin embargo, esta norma dispuso que para los demás espectáculos públicos con animales (peleas de gallos, circos con animales, etc.), cada municipio goza de discrecionalidad para reglar el tema. Esta norma ambiental implica un incumplimiento del legislador a lo establecido en cantones como Quito donde la ciudadanía se pronunció a favor de prohibir los espectáculos que tuviesen por finalidad dar muerte a un animal, lo que conlleva a una violación expresa del art. 106 de la CRE, sobre el efecto vinculante de las consultas populares.

En cuanto al nivel de eficacia de la norma, cabe recordar que la finalidad que perseguía el presidente de turno y la ciudadanía que votó a favor del SI era detener la crueldad animal; no obstante, este tipo de espectáculos se han seguido realizando por lo que el sufrimiento animal no ha sido eliminado. 


\section{La consulta popular y el referendo sobre limitación a la explotación minera y petrolera}

El 4 de febrero de 2018, por segunda ocasión, el pueblo ecuatoriano acudió a las urnas para pronunciarse sobre dos temas relacionados con la protección de la naturaleza. La primera pregunta versó sobre la prohibición de minería metálica bajo ciertas circunstancias; mientras que, la segunda pregunta, instó a que la ciudadanía se pronuncie respecto a la prohibición de la explotación petrolera en determinados casos. La iniciativa electoral, respecto a ambos temas sobre la protección a la naturaleza, provino del actual presidente de Ecuador -Lenin Moreno-. En esta ocasión, la Corte Constitucional incumplió su deber de realizar un control previo dentro del plazo fijado por la ley a fin de determinar la constitucionalidad de las preguntas propuestas (LOGJCC, art. 105 y art. 127); consecuentemente, aplicando las reglas del silencio administrativo positivo, se produjo un dictamen de constitucionalidad tácito y estas preguntas fueron llevadas a las urnas tal como se plantearon en un inicio. Se procede al análisis de cada una de las dos preguntas.

A) El referendo como mecanismo para limitar la extracción minera en Ecuador

Tras la caída del precio del petróleo en 2014, la agenda política ecuatoriana apostó todos sus esfuerzos a la explotación minera. La legislación vigente es favorable a los procesos extractivistas mineros. Efectivamente, el art. 30 y 31 de la Ley de Minería de 29 de enero de 2009 autorizan las concesiones mineras a gran escala, las mismas que impiden la protección a los derechos de la naturaleza y a los derechos humanos de las comunidades que habitan en las zonas donde se ejecuta la explotación. Respecto a los impactos ambientales de la mega-minería, Sacher y Acosta señalan:

La minería a gran escala implica la generación de desechos en proporciones extraordinarias. Para los metales no preciosos, generalmente más del $99 \%$ de la roca procesada se convierte en desecho, la producción de una tonelada de cobre implica la generación de un promedio de 300 a 500 toneladas de desechos. En el caso de 
los metales preciosos, los niveles de residuos son aún más altos: la producción de $10 \mathrm{~g}$ de oro (equivalente a un anillo) genera un promedio de 20 a 60 toneladas de desechos rocosos, así como 7.000 litros de agua contaminada con cianuro, sustancia cuya alta toxicidad es conocida. La ecuación es simple: a menor concentración, más desechos. Al final de la vida útil de la mina, millones de toneladas de residuos se acumulan, con múltiples riesgos de contaminación en suelo y agua. Los casos más comunes son por drenaje ácido de mina y metales pesados; igualmente la contaminación del aire es frecuentemente provocada por polvo cargado de metales pesados, como arsénico, cadmio, níquel, e incluso minerales radiactivos (Sacher, Acosta, 2012, p. 75).

La ley minera fue fuertemente criticada por los movimientos ecologistas y los pueblos indígenas. En marzo de 2009, la Confederación de Nacionalidades Indígenas del Ecuador CONAIE, los Sistemas Comunitarios de Agua de las Parroquias Tarqui, Victoria del Portete y otras comunidades de la provincia del Azuay presentaron una acción de inconstitucionalidad en contra de la Ley minera por la supuesta violación a varias disposiciones constitucionales y a ciertos instrumentos internacionales. El máximo órgano de control constitucional ratificó la constitucionalidad de esta ley y en la actualidad existen 5 megaproyectos mineros concesionados a empresas extranjeras (Ministerio de Minería, 2018). Por lo tanto, en la Cordillera del Cóndor -El Mirador-, en el cantón Cuenca -Río blanco-, en el cantón San Juan Bosco -San Carlos Panantza-, en el cantón Yanzatza -Fruta del Norte- y en la Cordillera Occidental de los Andes -Loma larga- ya se pueden visualizar los conflictos territoriales que surgen a partir de la autorización estatal a la minería a gran escala.

A modo de ejemplo, Sánchez, Leifsen y Verdú explican que, respecto al Proyecto Mirador, se evidencia un conflicto socio-ambiental, debido al daño ecológico y social que esta industria genera. Dichos autores abordan, por un lado, la incompatibilidad entre el desarrollo económico que se espera mediante la agresiva explotación a cielo abierto en las minas, con la justicia reclamada por las poblaciones afectadas, en muchos casos en procesos de expropiación de sus tierras u obligadas a desplazarse fuera de sus territorios 
de origen. Por otro lado, los autores evidencian el proceso de resistencia al Proyecto Mirador llevado a cabo por una alianza entre pequeños agricultores y ganaderos de origen mestizo e indígenas shuar $(2017,2)$.

Cabe recordar que, hasta antes del referendo de 4 de febrero de 2018, el art. 407 de la Carta Magna prohibía la actividad extractiva de recursos no renovables en áreas protegidas-ricas en biodiversidad- y en zonas intangibleshabitadas por los pueblos en aislamiento voluntario-, incluida la explotación forestal. Excepcionalmente, dichos recursos podían explotarse a petición fundamentada de la Presidencia de la República y previa declaratoria de interés nacional por parte de la Asamblea Nacional, órgano que, de estimarlo conveniente, podía convocar a consulta popular. Tras el referendo del 4 de febrero de 2018 se mantiene la potestad de la Asamblea Nacional de emitir una declaratoria de interés nacional para la explotación de los recursos naturales. No obstante, en dicho referendo, el gobierno apostó por la modificación del art. 407 de la CRE a fin de prohibir la minería, no únicamente en áreas protegidas y zonas intangibles, sino también en centros urbanos. La justificación del presidente de la república para convocar a referendo se basó en la necesidad de ampliar la protección de los derechos de la naturaleza:

El nuevo modelo económico planteado es un proceso no extractivista, el cual parte desde la cosmovisión indígena, sustentado por el principio del buen vivir o Sumak Kawsay...Este nuevo modelo implica el reconocimiento de otros derechos como el de la naturaleza, derecho de la tierra, soberanía alimentaria, protección de la biodiversidad, conocimientos ancestrales, lo que claramente es una propuesta válida ante el modelo caduco y extractivista neoliberal, donde el sujeto de derechos, es decir el individuo, se aprovecha de manera indiscriminada de los recursos del planeta, poniendo en riesgo a la humanidad a cambio de sus grandes ganancias particulares (Corte Constitucional, caso 2-17-RC).

Cabe señalar que el art. 18 de la Ley orgánica de ordenamiento territorial uso y gestión de suelo-LOTUGS- divide al suelo en urbano y rural. Esta norma define al suelo urbano como aquel que es "ocupado por asentamientos humanos concentrados que están dotados total o parcialmente de infraestructura básica y servicios públicos, y que constituye un sistema 
continuo e interrelacionado de espacios públicos y privados". Por lo tanto, en el suelo rural ${ }^{5}$ la minería puede continuar realizándose.

La pregunta de referendo tuvo un apoyo popular nacional del 68,62\%. Un aspecto que cabe resaltar es que la pregunta promovida por el presidente de la república remitía a un anexo que explicaba a detalle la modificación constitucional. Este anexo mantiene la excepción prevista desde 2008 en la Constitución, esto es:

Excepcionalmente dichos recursos se podrán explotar a petición fundamentada de la Presidencia de la República y previa declaratoria de interés nacional por parte de la Asamblea Nacional, que, de estimarlo conveniente, podrá convocar a consulta popular (CRE, art. 407)

Por lo tanto, estamos frente a una consulta popular que, aunque parece estar encaminada a la protección de la naturaleza, en la práctica no implica ningún cambio significativo por tres razones que se proceden a detallar. Primero, la prohibición de la minería metálica surte efectos en zonas urbanas; sin embargo, es en el suelo rural donde se encuentran los mega-proyectos mineros. Inclusive, la LOTUGS permite la explotación minera en zonas rurales, salvo que se trate de un suelo calificado como rural de producción, de expansión urbana o de protección (art. 19). Cabe señalar que, aunque de acuerdo a la Constitución, el gobierno central mantiene la competencia para administrar los recursos naturales no renovables (art. 313), la LOTUGS establece que los GADs cantonales son la autoridad competente para declarar el suelo rural como apto para aprovechamiento extractivo (art. 19). Esta potestad otorgada a los cantones es bastante criticable si tomamos en cuenta que el art. 274 de la CRE señala que los GADs, en cuyo territorio se exploten $\mathrm{o}$ industrialicen recursos naturales no renovables, tienen derecho a participar de las rentas que perciba el Estado por esta actividad. Consecuentemente, si estos gobiernos seccionales son beneficiarios de los réditos producidos por la extracción de minerales, resulta poco probable que estos califiquen una zona rica en minerales como "suelo urbano".

5 El art. 19 de la LOTUGS define al suelo rural como aquel destinado principalmente a actividades agroproductivas, extractivas o forestales, o el que por sus especiales características biofísicas o geográficas debe ser protegido o reservado para futuros usos urbanos. 
Segundo, se mantiene la misma excepción que existía antes del referendo; es decir, en caso de que se pretenda explotar un área protegida o un centro urbano se requiere una declaratoria de interés nacional emitida por la Asamblea Nacional, bajo petición presidencial. Cabe señalar que, en ocasiones anteriores, la Asamblea Nacional decidió la explotación de recursos naturales no renovables a través de la emisión de una declaratoria de interés nacional. Esto ocurrió a propósito de la autorización que se requería para explotar el petróleo del Parque Nacional Yasuní, calificado como área protegida.

Tercero, la prohibición de explotación minera a partir de la reforma constitucional se limita a zonas que hayan sido declaradas áreas protegidas, zonas intangibles y centros urbanos. No obstante, en Ecuador existen miles de hectáreas de ecosistemas frágiles -páramos, humedales y bosques protectores- que no ostentan el título requerido jurídicamente para ser objeto de protección. Sin embargo, son fuentes importantes de agua y constituyen el hábitat de cientos de especies. Este es el caso del bosque protector Molleturo-Mollepungo y la zona de amortiguamiento del Parque Nacional Cajas que, aunque no han sido calificadas expresamente como "áreas protegidas", representan zonas altamente biodiversas y corren el riesgo de ser contaminadas, por encontrarse dentro del área de explotación del proyecto minero Río Blanco. De ahí que hubiese sido oportuno que la iniciativa de referendo incluya a los ecosistemas frágiles como zonas excluidas a la actividad minera.

B) La protección de los ecosistemas y de los PIA en el Parque Nacional Yasuní

El parque Nacional Yasuní es la zona más biodiversa del planeta por metro cuadrado, declarado por la Organización de las Naciones Unidas para la Educación, la Ciencia y la Cultura-UNESCO-, como Reserva de la Biosfera; $\mathrm{y}$, donde habita la nacionalidad indígena Waorani y los pueblos indígenas en aislamiento -PIA- Taggaeri y Taromenane (Montilla, Guzmán, 2018, p. 18). Por su riqueza y diversidad de ecosistemas, el Yasuní es considerado como área protegida desde 1979. Adicionalmente, por ser el hogar de los PIA, una parte del Yasuní está calificada como zona intangible. De acuerdo al art. 407 
de la CRE está prohibida la actividad extractiva de recursos no renovables en las áreas protegidas y zonas intangibles.

En el año 2008, el ex presidente de la República-Rafael Correa-, mediante Decreto ejecutivo No. 847 de 2 de enero de 2008, publicitó la Iniciativa Yasuní -ITT como parte de una política pública, por medio de la cual Ecuador se comprometía a mantener indefinidamente inexplotadas reservas superiores a 840 millones de barriles de petróleo que correspondían al $90 \%$ de las reservas probables a cambio de una compensación económica equivalente al $50 \%$ de las ganancias que podían ser obtenidas como producto de la explotación -USD \$3.600 millones- (Ministerio Coordinador de la Política Económica, 21 de agosto de 2013). Tras cinco años de negociaciones, Rafael Correa informó a la comunidad internacional el fracaso de la iniciativa, aduciendo para ello, la falta de cooperación económica internacional. Inmediatamente, se elaboraron informes técnicos, económicos y jurídicos para solicitar a la Asamblea Nacional, la aprobación de la "declaratoria de interés nacional", acto público indispensable para dar paso a la explotación petrolera al interior del parque. Tras justificar la legalidad de su decisión, el 3 de octubre de 2013, la Asamblea Nacional autorizó la explotación de los bloques petroleros 31 y 43 ubicados dentro del Parque Nacional Yasuní. A fin de justificar su decisión, el poder legislativo argumentó la necesidad de cumplir con el deber estatal de redistribuir equitativamente los recursos y erradicar la pobreza (CRE, art. 3), objetivo que se alcanzaría con los réditos obtenidos del petróleo. Adicionalmente, la Asamblea sostuvo que la explotación petrolera se haría respetando los estudios de impacto ambiental y los planes de manejo ambiental a fin de evitar daños a la naturaleza.

La inconformidad de esta decisión legislativa por parte de ciertos grupos sociales conllevó a que el colectivo ecologista Yasunidos haga uso de la iniciativa ciudadana para promover una consulta popular nacional que impidiese al gobierno de turno explotar los bloques petroleros mencionados. Para ello, de acuerdo a lo previsto en la CRE, Yasunidos debía contar con el respaldo de un número no inferior al $5 \%$ de las personas inscritas en el registro electoral (CRE, art. 104). La pregunta que se pretendía someter a consulta era: ¿Está usted de acuerdo con que el gobierno mantenga el crudo del ITT, conocido como bloque 43, indefinidamente bajo el suelo? Esta pregunta tenía 
por finalidad evitar la contaminación proveniente de la actividad petrolera y de este modo garantizar el cumplimiento de dos disposiciones constitucionales. Por un lado, el art. 397 de la Carta Magna establece el deber estatal de asegurar la intangibilidad de las áreas naturales protegidas, de tal forma que se garantice la conservación de la biodiversidad y el mantenimiento de las funciones ecológicas de los ecosistemas. Por otro lado, el art. 57 de la norma suprema establece que los territorios de los pueblos en aislamiento voluntario son de posesión ancestral irreductible e intangible, y en ellos está vedada todo tipo de actividad extractiva.

El proceso de recolección de firmas duró seis meses (octubre 2013 - abril 2014). Una vez realizado el conteo de firmas, el Consejo Nacional Electoral-CNE-, institución encargada de validar las firmas, informó públicamente que Yasunidos no obtuvo las firmas necesarias para convocar a una consulta popular; sin embargo, la organización ecologista alegó que se dieron irregularidades durante el procedimiento de conteo y validación de firmas (El Comercio, 6 de mayo de 2014). Posteriormente, el colectivo ecologista presentó varias acciones tendientes a lograr que se realice la consulta popular propuesta, sin que hasta el momento hayan obtenido una respuesta favorable. ${ }^{6}$ Por lo expuesto, a partir del año 2014 se extrae crudo del Parque Nacional Yasuní; y, las críticas a los efectos de dicha decisión no se han hecho esperar.

Expertos en el tema afirman que, la tecnología empleada para la extracción petrolera en el Yasuní no satisface los requisitos de explotación establecidos en la declaratoria de Interés nacional; y, que existen estudios realizados con fotos satelitales que evidencian que se construyeron carreteras aptas para la circulación de vehículos pesados que requieren una infraestructura de gran escala que provoca mayor impacto y contaminación para la biodiversidad de la zona (Larrea 2015, p. 3). Adicionalmente, se ha señalado que el abarcamiento de un área tan extensa de explotación con 40 cámaras trampa para monitorear las condiciones de la fauna que se moviliza en el área y la presencia de pueblos no contactados, resulta insuficiente para determinar con certeza si la zona de explotación sería lugar de tránsito, caza,

6 Ecuador, Tribunal Contencioso Electoral, sentencia de la causa No. 888-2019-PCE, 21 de enero de 2020 
pesca o de asentamiento temporal de estos pueblos ancestrales (Aguilar, 7 septiembre 2016, p. 1).

Más tarde, en el año 2017, el presidente de turno-Lenin Morenopresentó una iniciativa de consulta popular referente al Yasuní justificándose en la necesidad de proteger a dos sujetos de derechos: a los PIA y a nuestra casa común llamada planeta Tierra, todo esto a la luz del art. 71 de la CRE que reconoce a la naturaleza como sujeto derechos y del art. 57, penúltimo inciso que señala que, "Los territorios de los pueblos en aislamiento voluntario son de posesión ancestral irreductible e intangible, y en ellos estará vedada todo tipo de actividad extractiva" (Corte Constitucional, caso 1-17-CP). Esta consulta puso a consideración de la ciudadanía si, ¿Está usted de acuerdo en incrementar la zona intangible en al menos 50.000 hectáreas y reducir el área de explotación petrolera autorizada por la Asamblea Nacional en el Parque Nacional Yasuní de 1.030 hectáreas a 300 hectáreas? Dicha pregunta fue respondida de manera afirmativa por el $67,31 \%$ de la población ecuatoriana.

A fin de establecer la eficacia de la consulta popular hay que comenzar recordando que, la convocatoria de 4 de febrero de 2018 no fue tan ambiciosa, si se la compara con el planteamiento presentado por el colectivo Yasunidos cuatro años atrás. Efectivamente, la iniciativa ciudadana presentada en el año 2014 pretendía prohibir de manera absoluta la explotación del Yasuní. Por el contrario, la iniciativa de 2018, a cargo del presidente de la República, legitima la explotación petrolera salvo dos limitaciones impuestas: 1) que se reduzca el área de explotación y 2) que se aumente el área de protección.

Recordemos que mediante decreto ejecutivo Nro. 2187 de 16 de enero de 2007, se estableció una zona de amortiguamiento ${ }^{7}$ de diez kilómetros de ancho contiguo a toda la zona intangible de los PIA con el objeto de prohibir la realización de actividades extractivas de productos forestales, concesiones mineras, obras de infraestructura tales como carreteras, centrales hidroeléctricas, centros de facilidades petroleras; y, otras obras que los estudios técnicos y de impacto ambiental juzguen incompatibles con el objeto

7 Código Orgánico del Ambiente, art. 59: Las zonas de amortiguamiento ambiental serán áreas colindantes a las áreas del Sistema Nacional de Áreas Protegidas o a las zonas de expansión urbana, que sean de propiedad pública, privada o comunitaria, para contribuir a la conservación y la integración de las áreas protegidas, el equilibrio en el desarrollo urbano-rural y su conectividad ecosistémica. 
de la zona intangible (art. 2 y 3). Sin embargo, el 21 de mayo de 2019, la presidencia de la República, contrariando la voluntad popular plasmada en las urnas, emitió el Decreto Ejecutivo No. 751 cuyo art. 3 dispone que "se exceptúa de la prohibición expresada en el artículo 3, a las plataformas de perforación y producción de hidrocarburos", lo que pone en riesgo a los PIA que transitan por la zona de amortiguamiento y a la biodiversidad presente en dicha área (Narváez, Pichilingue, Maldonado, 2019, p. 2-10).

Por lo tanto, los resultados plasmados en las urnas en 2018 no tuvieron la eficacia esperada, puesto que, si bien en principio, el presidente de la republica justificó la iniciativa popular en la necesidad de efectivizar la protección a la naturaleza presente en el Parque Yasuní y a los PIA que ahí habitan, el decreto No. 751 impide una tutela estatal adecuada. Adicionalmente, tanto el art. 71 - derechos de la naturaleza- como el art. 57, penúltimo inciso - protección a los pueblos no contactados-, no han tenido la efectividad deseada puesto que la norma emitida por el ejecutivo viola inminente dichas disposiciones constitucionales.

Debido a que la democracia y la soberanía popular no se agotan en las urnas, siempre existe la posibilidad de reclamar y oponerse a las decisiones que toma el aparataje estatal. Da ahí que un grupo de ciudadanos haya presentado una acción de inconstitucionalidad en contra del decreto ejecutivo No. 751 aduciendo la violación de varias disposiciones constitucionales, entre ellas el art. 106 respecto al efecto obligatorio de la consulta de febrero 4 de 2018; y, el art. 57 \#12 sobre la recuperación, promoción y protección de plantas, animales, minerales y ecosistemas dentro de sus territorios. Esta demanda fue aceptada a trámite el 26 de septiembre de 2019 y al momento se encuentra a la espera de un pronunciamiento por parte de la Corte Constitucional (Corte Constitucional, caso N. 0028-19-IN, 26 de septiembre de 2019).

Se debe tener presente que si bien en principio, el decreto ejecutivo No. 751 incrementa la zona intangible de 758.051 hectáreas a 818.501,42 hectáreas, surgen tres cuestionamientos a esta nueva delimitación: 1) ¿La nueva superficie autorizada es suficiente para salvaguardar la vida de los pueblos en aislamiento? Esta interrogante nace porque los pueblos Tagaeri y Taromenane son pueblos nómadas que necesitan vastos territorios para 
desarrollar sus actividades cotidianas-pesca, caza, etc.-; 2) ¿El perímetro fijado se basa en estudios antropológicos, sociológicos, cartográficos que evidencien que la superficie de 818.501,42 hectáreas es suficiente para proteger a los PIA?; y, 3) ¿El Estado cuenta con los recursos humanos, técnicos y financieros para evitar actividades ilegales como deforestación o tráfico de animales en el perímetro protegido? Dichas preguntas no fueron solventadas con la emisión del decreto ejecutivo No. 751.

\section{Conclusiones}

Si bien en principio, la iniciativa para que se lleven a cabo los tres procesos electorales celebrados en Ecuador sobre temas de protección de la naturaleza ha provenido de la función ejecutiva, cabe recordar que la sociedad civil-pueblos indígenas, organizaciones ecologistas, animalistas, etc.-, son quienes de manera permanente reivindican la necesidad de proteger los derechos humanos y de la naturaleza. De ahí que el activismo social, haciendo uso del derecho a la participación, presente demandas judiciales, iniciativas normativas y peticiones al poder público a fin de que este tome en cuenta la necesidad de evitar el maltrato animal, el extractivismo a gran escala y la destrucción de los ecosistemas.

Partiendo de la premisa bajo la cual, el manejo de los recursos estratégicos, dependiendo de la forma en que se administren, puede beneficiar o perjudicar a toda la población ecuatoriana, es necesario que la ciudadanía se empodere del derecho de participación a fin de controlar y fiscalizar cualquier norma o política pública que pueda tener un impacto negativo en la naturaleza. Si bien en principio, la consulta popular y el referendo son mecanismos de participación directa que permiten frenar los abusos cometidos por las políticas públicas extractivistas, es lamentable que las dos ocasiones en que se convocó al pueblo a las urnas para pronunciarse sobre temas de protección a la naturaleza, la iniciativa haya provenido de la función ejecutiva. Desafortunadamente, la iniciativa ciudadana planteada por Yasunidos deja notar que cuando las iniciativas ecológicas provienen de grupos organizados de la sociedad civil, ha sido la misma institucionalidad, quien se rehúsa a que se efectivice el derecho de participación. 
Las preguntas planteadas por el ejecutivo respecto a los tres temas analizados visibilizan la ausencia de eficacia jurídica, puesto que no se logró la intención del proponente ni tampoco se respetó la voluntad popular. Efectivamente, el ejecutivo justificó sus iniciativas de consultas populares y referendo en la necesidad de frenar la crueldad animal y proteger los derechos de la naturaleza y los derechos de los pueblos indígenas. Sin embargo, en la práctica, se continúan celebrando espectáculos que implican actos de maltrato y crueldad animal, se siguen expandiendo los proyectos mineros y se está aumentando el área de explotación petrolera en el Yasuní. Todo ello deja ver que la voluntad del pueblo visibilizada en las urnas, aún no logra consolidarse en las normas, decisiones judiciales y políticas públicas ecuatorianas.

Lejos de alinearnos a lo expuesto por Rodrigo Borja respecto a que la democracia directa es un imposible físico porque no hay manera de que el pueblo, masivamente, tome en sus manos la conducción de sus destinos (2018), esta investigación sostiene que el ejercicio de la democracia directa es una vía idónea para involucrarse de manera permanentemente en la administración del Estado. Para ello, se requiere pensar en dos problemáticas que deben ser resultas simultáneamente. Por un lado, se debe reflexionar urgentemente sobre la viabilidad de nuevos mecanismos que fomenten y tutelen las iniciativas ciudadanas y no únicamente las iniciativas presidenciales; solo así se limitará la tergiversación de la democracia directa que en la actualidad se limita a solicitar la aceptación ciudadana una vez que el aparataje estatal ha decidido previamente tres aspectos: 1) los temas que se consultan, 2) la forma en qué se consulta; $y, 3$ ) el resultado que se pretende alcanzar tras realizar la consulta popular o referendo.

Por otro lado, no se puede olvidar que el poder constituido tiene la obligación de dar cumplimiento irrestricto a lo expresado por el poder constituyente en Montecristi en 2008, en el art. 106 de la Carta Magna respecto al efecto vinculante que detentan las consultas populares y los referendos; y en el art. 71 que reconoce a la naturaleza como sujeto de derechos. De ahí que el aparataje estatal deba crear los mecanismos necesarios para garantizar la eficacia y la efectividad de la participación ciudadana en su calidad de derecho constitucional inalienable, irrenunciable, indivisible y de igual jerarquía. Si verdaderamente queremos detener la degradación de la calidad de vida de 
CONSULTAS POPULARES Y REFERENDOS CONSTITUCIONALES SOBRE LA PROTECCIÓN A LA NATURALEZA: LA EFICACIA DE LA DEMOCRACIA DIRECTA EN ECUADOR

los ecuatorianos a causa de la contaminación y proteger los ecosistemas por su rol dentro de los ciclos vitales y los procesos evolutivos y por su valor intrínseco, debemos asegurarnos que los derechos de participación ciudadana sean ejercidos de manera interdependiente y complementaria con los derechos de la naturaleza. 


\section{Bibliografía}

\section{Obras}

Bethencourt, Tonio (1982). "Las peleas de gallos en Tenerife en el setecientos", Revista Anuario de estudios atlánticos, Número 28, Madrid, Editorial Cabildo Insular de Gran Canaria.

Borja, Rodrigo (2018). Enciclopedia de la política https://www. enciclopediadelapolitica.org/democracia_directa/

Castañeda, Nathalia (2015). Animalismo pragmático. Hacia la resignificación del valor de los animales en el desarrollo y un concepto más integral de sostenibilidad, Bogotá, Ediciones Uniandes.

Díez-Picazo, Luis (1999). Experiencias jurídicas y teoría del derecho, $3^{\text {a }}$ edic., Editorial Ariel S.A., Barcelona, 1999.

Donzis, Héctor (2006) "La eficacia social de las normas jurídicas", Revista electrónica de Teoría y Práctica de la Elaboración de Normas Jurídica”, Año II - Número IV -.

Friedman, Lawrence (2015). Il Sistema Giuridico nella Prospettiva delle Scienze Sociali, citado por Vincenzo Ferrari, "Funciones del Derecho", Ec. Debate. 2015

Kelsen, Hans \& Reine, Rechtslehre (1960). Teoría pura del Derecho. 2a y definitiva edición, revisada y ampliada. Viena. Trad. del original en alemán por R. J. Vernengo, México: Universidad Nacional Autónoma de México.

Monterín, Jesús, (2014). El triunfo de la compasión, primera edición, Colección Alianza Ensayo.

Montilla Argenis, Guzmán Diego (2018). Parque Nacional Yasuní, ecología y ecoturismo, Universidad Laica Eloy Alfaro de Manabí, Manabí.

Morales, Viviana (2020). "Las corridas de toros en Ecuador. Deconstruir la cultura taurina para construir los derechos de los animales", 
FORO Revista de Derecho, UASB, N. ${ }^{\circ} 4$ (julio-diciembre).

Narváez, Roberto, Pichilingue, Eduardo, Maldonado, Paola, (2019). "La amenaza del decreto ejecutivo No. 751 a la supervivencia de los pueblos en aislamiento Tagaeri Taromenane. Análisis antropológico, espacial y de derechos", mayo 2019, researchgate

Orwell, George (2017). Rebelión en la granja, traductor Miguel Souto y Marcial Temprano, editor: debolsillo; Edición: 007, España

Pavó Rolando (2016). "Las Investigaciones Sociojurídicas Acerca de la Eficacia y Efectividad del Derecho"; Algunas Alternativas Metodológicas, revista internacional consinter de direito, Publicação Oficial do Conselho Internacional de Estudos Contemporâneos em Pós-Graduação, ANO II NÚMERO II

Sacher William, Alberto Acosta (2012). La minería a gran escala en Ecuador. Análisis y datos estadísticos sobre la minería industrial en el Ecuador, Abya Yala, Quito

Sánchez Luis, Leifsen Esben, Verdú Ana (2017). "Minería a gran escala en Ecuador: Conflicto, resistencia y etnicidad", Revista de antropología iberoamericana, Vol. 12 Núm. 2 (2017): Mayo - Agosto

Velásquez, Fabio; González Esperanza (2004). La planeación participativa en Bogotá D.C. Análisis y propuestas, Colombia, Fundación Corona, Foro Nacional Pro Colombia, enero de 2004, Disponible en http:// www.fundacióncorona.org.co/descargas/planeaciónparticipativaenBogotá. pdf.

\section{Reportes e informes}

Aguilar Daniela, "Yasuní: Empieza la explotación petrolera en polémico bloque ubicado en la Amazonía ecuatoriana", Revista digital MongabayLatam, Ecuador, 7 septiembre 2016

International Institute for Democracy and Electoral Assistance, "Démocratie directe Un aperçu du Manuel d'International", Estocolmo, 
IDEA, 2009

Larrea Carlos, Notas sobre la rentabilidad de la explotación petrolera en el campo ITT, UASB, Ecuador, octubre 2015

Ministerio Coordinador de la Política Económica, Oficio Nro. MCPE-D201026, 21 de agosto de 3013

Organización de las Naciones Unidas para la Educación, la Ciencia y la Cultura-UNESCO-, "Glosario de términos sobre medio ambiente", Paris, 1989.

Ministerio de Minería, “Strategic mining projects”, febrero 2018

Ozafrin Lizandro, "Principio de mínima intervención, jurisdicción indígena y derechos humanos", Revista Anales de la Facultad de Ciencias Jurídicas y Sociales. UNLP. Año 13 / No 46 - 2016

\section{Fuentes normativas}

Constitución de la República del Ecuador, R.O. 449, 20 de octubre de 2008

Mandato Constituyente N. 6, R.O. No. 321, segundo supl., 22 de abril de 2008

Resultados de la Consulta Popular y Referendo de 7 de mayo de 2011, R.O. supl. $N^{\circ} 490,13$ julio del 2011

Resultados de consulta popular y referendo de 4 de febrero de 2018 , R.O. supl. $\mathrm{N}^{\circ} 180,14$ de febrero de 2018

Ley Orgánica de Garantías Jurisdiccionales y Control Constitucional, R.O. supl. 52, 22 de octubre de 2009

Ley orgánica de ordenamiento territorial uso y gestión de suelo, R.O. Supl. 790, 5 julio 2016

Ley Orgánica de Participación Ciudadana, R.O. Supl. 175, 20 abril 2010 
Ley de Minería, R.O. Supl. 517, 29 de enero de 2009

Ordenanza DM de Quito N. 106, 20 de octubre del 2003

Ordenanza DM de Quito reformatoria del capítulo III de los espectáculos taurinos N. 127, 3 de octubre de 2011

Decreto Ejecutivo No. 847 de 2 de enero de 2008, Ministerio de Economía

Defensoría del Pueblo de Ecuador, Resolución No. 014-DPEDINAPROT-56656-2013, 12 de junio de 2013

\section{Fuentes jurisprudenciales}

Corte Constitucional del Ecuador, Sentencia N. ${ }^{\circ} 001-18-\mathrm{SIN}-\mathrm{CC}, 27$ de febrero de 2018

Corte Constitucional del Ecuador, causa No. 0038-13-IS, 9 de julio de 2013

Corte Constitucional del Ecuador, Dictamen No. 001-DCP-CC-201, 15 de febrero de 2011

Corte Constitucional del Ecuador, Acción de inconstitucionalidad, caso No. 0056-11-IN.

Corte Constitucional del Ecuador, Sentencia N. 0 001-10-SIN-CC, 18 de marzo de 2010

Tribunal Contencioso Electoral, sentencia de la causa No. 888-2019PCE, 21 de enero de 2020

\section{Linkografia}

“Apuntes sobre la historia taurina de Quito- Ecuador", disponible en http://www.opinionytoros.com/tribuna.php?Id=1514

Juan Miguel Méndez, Mira: Balcón de los Andes, consultado el 20 de mayo de 2020, http://mira.ec/leyendas-y-tradiciones/gallos/ 
La Hora, 29 de agosto de 2018, consultado el 20 de mayo de 2020, https://www.lahora.com.ec/loja/noticia/1102181866/competencia-de-gallospor-fiestas-de-loja-

La Hora, 4 de noviembre de 2015, consultado el 15 de mayo de 2020, https://lahora.com.ec/noticia/1101881346/se-mantendrc3a1n-las-peleas-degallos-en-antonio-ante,

El Comercio, 6 de mayo de 2014, https://www.elcomercio.com/ actualidad/politica/firmas-recolectadas-yasunidos-no-alcanzan.html, consultado el 20 de abril de 2020 